\title{
Kernos
}

Revue internationale et pluridisciplinaire de religion grecque antique

20 | 2007

Varia

\section{SAUZEAU Pierre, Les partages d'Argos. Sur les pas des Danaïdes}

\section{Christoph Auffarth}

URL : https://journals.openedition.org/kernos/350

DOI : $10.4000 /$ kernos.350

ISSN : 2034-7871

\section{Éditeur}

Centre international d'étude de la religion grecque antique

\section{Édition imprimée}

Date de publication : 1 janvier 2007

Pagination : 416-417

ISSN : 0776-3824

\section{Référence électronique}

Christoph Auffarth, « sauzeau Pierre, Les partages d'Argos. Sur les pas des Danaïdes », Kernos [En ligne], 20 | 2007, mis en ligne le 17 mars 2011, consulté le 08 septembre 2022. URL : http:// journals.openedition.org/kernos/350 ; DOI : https://doi.org/10.4000/kernos.350 
$\mathrm{Au}$ fond, la faiblesse de cette étude réside dans deux postulats qui sont étroitement liés l'un à l'autre: 1) pour comprendre la personnalité d'Aphrodite, il faut regarder vers les prétendues origines de cette déesse, donc vers Chypre et l'Orient; 2) l'implication de cette Aphrodite « hellénisée » dans l'univers guerrier ne peut s'expliquer qu'en termes de renversement de rôles, de travestissement rituel, de paradoxe. Or, en l'état actuel de la documentation, Chypre n'a livré que trop peu d'indices, et relativement récents, sur le culte local d'une Aphrodite liée à la guerre. Face au riche dossier qui nous vient des cités grecques, nous sommes dans l'obligation d'évaluer avant tout la possibilité que ce lien trouve sa raison d'être dans la pensée religieuse des Grecs eux-mêmes. Ensuite, la présence d'Aphrodite dans l'univers d'Arès, étant donné la variété chronologique et typologique des sources qui en témoignent, ne peut se ramener à une explication unique, mais demande à être analysée cas par cas en fonction du contexte : à ce propos, est-il pertinent de faire appel aux tensions entre hommes et femmes, ou même entre citoyens et esclaves, pour expliquer les armes d'Aphrodite? À mon sens, loin d'être paradoxal, l'aspect guerrier que cette déesse peut parfois revêtir engage à comprendre la façon dont elle est censée contribuer à la victoire militaire et à la protection de la cité. Certes, Aphrodite n'est pas Athéna, mais, comme les sources anciennes le confirment, les Grecs étaient bien conscients des recoupements entre guerre et sexualité.

Malgré ces limites, l'étude de M.V. se signale par une attention constante à l'imbrication profonde entre religion et société, et par une riche bibliographie, bien exploitée. Si la méthode suivie et les conclusions de cet ouvrage n'emportent pas la conviction, il faut toutefois reconnaître à M.V. le mérite d'avoir fait une part dans son enquête aux liens qu'Aphrodite entretient avec la guerre dans les cités grecques, un dossier souvent négligé et pourtant fondamental pour pouvoir cerner cette déesse dans toute sa complexité.

$$
\begin{array}{r}
\text { Gabriella Pironti } \\
\text { (Centre Louis Gernet, EHESS - Paris) }
\end{array}
$$

SAUZEAU Pierre, Les partages d'Argos. Sur les pas des Danaïdes, Paris, Belin, 2005. 1 vol. $14 \times 21 \mathrm{~cm}, 395$ p. (L'Antiquité au présent). ISBN : 2-7011-3346-7.

Das hier zu besprechende Buch von Pierre Sauzeau (Université de Montpellier III) ist seine für den Druck überarbeitete Dissertation von 1994 an der Universität Lyon II bei Pierre Vidal-Naquet und Michel Casevitz. Die Fragestellung beider Doktorväter begründen das Interesse einmal an sprachwissenschaftlichen Beobachtungen und an den Bildern (imaginaire), die sich mit der Stadt Argos verbinden.

Argos ist nach Athen und Sparta mit Korinth und Theben die bedeutendste Stadt Griechenlands, hat aber ungleich weniger Interesse und Forschungen gefunden. Und das, obwohl die großen Ausgrabungen der Amerikaner schon früh das Material des Heraions zur Verfügung gestellt haben und die französischen und griechischen Grabungen in der Stadt kontinuierlich (seit Willem Vollgraff) neues wichtiges Material zu Tage brachten. Die archäologischen Befunde sind in dem vorzüglichen Band Argos et Argolide. Topographie et Urbanisme (1998) zusammengefasst worden. Über das frühe Argos hat Robin Hägg wertvolle Beobachtungen gemacht, die er hoffentlich noch mit dem zweiten Band krönen wird. Und in der Zusammenschau von Archäologie und Texten hat Marcel Piérart fast Jahr um Jahr neue Erkenntnisse beigesteuert über Argos und seine Religionsgeschichte. Argos wird in den Arbeiten von de Polignac zum einen der beiden Idealtypen der Entstehung der griechischen Polis. Aber eine Monographie über Argos fehlt immer noch. So liest man mit Spannung dieses Werk.

Teil 1 will aus dem Namen Argos philologisch die Fülle der Möglichkeiten und die Eigenschaften erschließen, über die die Stadt verfügt. Angesichts der häufigeren Vorkom- 


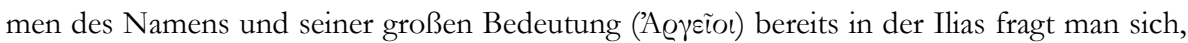
ob sich das Toponym von der Stadt in der Peloponnes ausbreitete. Man sieht S.' Ausbildung, wenn sich der Etymologe strikt anders entscheidet: Argos sei das "leuchtendstrahlende Land" (S. 29). Sogar für Hera 'Agyeín argumentiert er dafür, dass das nicht die Hera von Argos, sondern wiederum die strahlende Göttin als Souveräne des strahlenden Königreiches sei. Toponym als Epiklese ist aber auch angesichts der Verbreitung weitaus plausibler. Wie die Geschichte der Argo-Expedition, der Argonauten unter dem Schutz der Hera, zu ihrem Namen gekommen ist, ist ungeklärt, bleibt es auch nach den Erklärungen des Etymologen. Er geht noch einen Schritt weiter, indem er die Zweiteilung der Argolis in den hellen, aber trockenen Teil und den dunklen, feuchten Teil wieder aus der Etymologie zu erklären versucht. Der Mythos beschreibt den Streit zwischen Poseidon und Hera (ähnlich dem zwischen Poseidon und Athen in Attika), in dem der Begründer der mythischen Königsdynastie, Inachos, die Partei der Göttin ergreift. So kommt es zu der trockenen Ebene der Hera (Teil 2) und der feuchten Seite mit Lerna-See und Karstquelle des Poseidon (Teil 3). Die Poseidon-Seite stellt S. in die Verbindung mit Arkadien, betont die chthonischen Verbindungen, den Einstieg in die Unterwelt. So entsteht ein Dualismus zwischen der Hellen und dem Chthonischen. Hier wäre allerdings weniger zu beobachten, wie Poseidon im Mythos der Verlierer wird, sondern wie Poseidon in der Peloponnes eine hohe Dichte von Heiligtümern am Meer besitzt. ${ }^{1}$ Und das andere: Die trockene Seite kann die Pferdezucht und die Kühe der Hera schlecht nähren: Was also will der Mythos über das Verhältnis von Reichtum und Politischer Herrschaft sagen? Die Ambivalenz der Mythen ist doch entscheidend, nicht der Sieg eines Gottes über den anderen. Wieder arbeitet S. eher strukturalistisch, wenn er (Teil 4) die Stadt Argos zur "Vermittlerin" zwischen den beiden Hälften erklärt. Das Problem, ist das Heraion ein extraurbanes Heiligtum oder ein regionales Heiligtum aller 'Städte' der Argolis, das später unter die Herrschaft der Stadt Argos kam, wird nicht diskutiert. ${ }^{2}$ Hera vs. Apollon, für die Entstehung der Polis eine zentrale Konfrontation, kommt nicht in den Blick. Dagegen hebt S. die hohe Bedeutung der femininen Akteurinnen hervor für die Stadt und ihre Identität.

Hat man den strukturalistischen Blick akzeptiert, dann bietet das Buch, besonders im letzten Teil über den Mythos der Danaiden, ${ }^{3}$ eine Fülle vorzüglicher Beobachtungen und eine Diskussion auf neuestem Niveau. Man wird sie für eine Religionsgeschichte berücksichtigen müssen und dankbar die Diskussion des Mythos rezipieren. Nur: eine religionswissenschaftliche und historische Monographie zur Religion von Argos unter Einbeziehung der Archäologie kann, das will Sauzeau nicht bieten.

Christoph Auffarth (Universität Bremen)

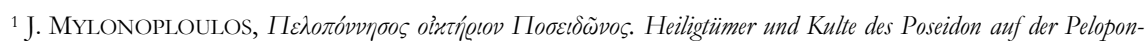
nes, Liège, 2003 (Kernos, suppl. 13).

2 Fr. De Polignac, La naissance de la cité grecque, Paris, 1984, rückt in der am. Übersetzung 1995 völlig ab vom Strukturalismus in Richtung auf historische Entwicklungen; J. HALL, "How Argive is the Argive Heraion?", AJA 99 (1995), p. 577-613; Chr. AufFARTH, "Das Heraion von Argos oder das Heraion der Argolis? Religion im Prozeß der Polisbildung”, in Kl. FreITAG, P. FunKE; M. HAAKE (Hrsg.), Kult- Politik Ethnos. Überrregionale Heiligtümer im Spannungsfeld von Kult und Politik, Stuttgart, 2006 (Historia-Einzelschriften, 189), p. $73-87$.

${ }^{3}$ Ein religionshistorischer Versuch bei Chr. AUFFARTH, "Constructing the identity of the polis: the Danaides as 'ancestors", in R. HÄGG (Hrsg.): Ancient Greek Hero Cult. Proceedings of the International Seminar Götebory 1995, Stockholm, 1999, p. 39-48.
} 